\title{
Reflections on the Contributions of Sidney J. Blatt: The Dialectical Needs for Autonomy, Relatedness, and the Emergence of Epistemic Trust
}

\author{
Patrick Luyten \\ KU Leuven and UCL (University College London) \\ Chloe Campbell and Peter Fonagy \\ UCL
}

Author Note

Patrick Luyten, Faculty of Psychology and Educational Sciences, KU Leuven, and Research Department of Clinical, Educational and Health Psychology, UCL; Chloe Campbell, Research Department of Clinical, Educational and Health Psychology, UCL; Peter Fonagy, Research Department of Clinical, Educational and Health Psychology, UCL.

Correspondence concerning this article should be addressed to Patrick Luyten, Faculty of Psychology and Educational Sciences, KU Leuven, Tiensestraat 102, Box 3722, 3000 Leuven, Belgium. E-mail: patrick.luyen@kuleuven.be

This article is based in part on a paper presented at the Special Grand Rounds in Honor of Sidney J. Blatt, PhD, Yale School of Medicine, Department of Psychiatry, New Haven, CT, December 16, 2011. 


\begin{abstract}
This paper, written to commemorate the fifth anniversary of Sidney J. Blatt's death, addresses the legacy of his work on autonomy and relatedness as fundamental dimensions in normal and disrupted personality development. We begin this paper by exploring what it was about Blatt's contributions in this area that made it so resonant and valuable to the wide community of clinicians and academics. The second part of the paper reflects on how his thinking has influenced our own work concerning the origins of human subjectivity and its role in normal and disrupted development. We argue that our views concerning the role of attachment and mentalizing in developing the capacity for epistemic trust and salutogenesis are highly organized around Blatt's conception of the human dilemma arising from the dialectical needs for relatedness and an autonomous, agentive self. We also discuss the similarities in our views concerning the parallel between normal developmental processes and the therapeutic process, with a focus on the importance of experiences of mutuality and understanding versus separation and misunderstanding in both.
\end{abstract}

Keywords: Depression, object relations, attachment theory, personality, mentalizing. 
CONTRIBUTIONS OF SIDNEY J. BLATT

Sidney Blatt made rich and wide-ranging contributions to the fields of personality development, psychology, and psychopathology. The great number of obituaries and special sections and issues that have been devoted to him and his work (e.g., Auerbach, 2016; Luyten, 2015; Oasi \& Auerbach, 2017; Shahar \& Mayes, 2017) testifies to this. In this paper, written to commemorate the fifth anniversary of his death, we will reflect on some of his key contributions. We will divide the paper into two halves. We will begin, in anaclitic style, by exploring what it was about Blatt's work that made it so resonant and valuable to the wide community of clinicians and academics alike, and how his thinking addressed some of the most troubling complexities that have beleaguered and divided the world of developmental psychopathology and human beings more generally. In the second half of the paper, in a rather more introjective manner, we reflect on how his thinking has shaped our own work, and examining how our current approach can, in many ways, be viewed as highly organized around Blatt's conception of the human dilemma arising from the dialectical needs for relatedness and an autonomous, agentive self. We will finish by proposing an integrative resolution of these two poles.

\section{The Two-Polarities Model: Blatt's Major Contribution to the Field}

The two-polarities model formulated by Blatt describes a dialectic relationship between self-definition (the introjective pole) and relatedness (the anaclitic pole) in personality development and psychopathology (Blatt, 2008; Blatt \& Blass, 1996; Blatt \& Luyten, 2009). It is via the individual's location on this dimension, delineated by the two polarities, that personality state is calibrated. We suggest that it is in the idea of a dialectic between these poles that an element of Blatt's great creativity lies. Through the idea of this dialectic — and the creativity, conflict, and resolution that it involves - Blatt avoided the dangers of an overly deterministic model. An account of the dynamic relationship between 
self-definition and relatedness created a model that allowed more movement, complexity, and interaction in terms of an individual's position on this dimension; and, from a clinical perspective, this model allowed for hope. A dialectic by its very nature involves dynamic changes and the potential for resolution; as described by Blatt, each individual's condition contained this creative struggle and possible integration.

We begin our paper with this point because it reflects some key underpinning themes of Blatt's work and style of thinking that in themselves constitute a major contribution. In an intellectual sphere in which different camps have traditionally been so forcefully oppositional and rigidly differentiated - around issues such as the use of empiricism, thinking about when classical psychoanalysis might be the most appropriate treatment (and, critically, when it might not), and the controversies about integrating psychodynamic thinking with other cognitive and developmental approaches_-Blatt boldly and calmly embraced a creative dialectic. In doing so, he generated a new way of thinking about depression (Blatt, 2004) and personality disorder that responds to some of the many problems that have dogged clinical and diagnostic conceptualizations of these disorders (Luyten \& Blatt, 2013). Why is there such a gap between diagnostic category and predicted therapeutic response, and whydespite rapid advances in neuroscience - have we been unable to find adequate links between diagnostic categories and underlying pathophysiology (Ghaemi, 2018; Kapur, Phillips, \& Insel, 2012; Rutter, 2013; Uher \& Rutter, 2012; Zachar \& Kendler, 2017)? By reconceptualizing different types of psychopathology as reflecting impairments in the dialectic between self-definition and relatedness at different developmental levels, Blatt provided a framework for thinking about clinical symptoms differently. Anaclitic and introjective dimensions in depression may have quite different developmental origins and implications for treatment (Blatt, 2008; Luyten \& Blatt, 2013). Anaclitic depression is characterized by loneliness, abandonment, and neglect, while introjective depression is 
dominated by feelings associated with self-worth, failure, and guilt (Blatt \& Marouidas, 1992). Blatt suggested that thinking about an individual's depressive style in relation to their location on the anaclitic-introjective dimension could guide decisions about the most effective form of treatment (Blatt \& Ford, 1994; Blatt, 1992; Blatt, Besser, \& Ford, 2007; Fertuck, Bucci, Blatt, \& Ford, 2004) in a manner that broke the taxonomic/treatment impasse of the existing framework for depression.

This assumption was first explored by Blatt and Shahar (2004) using data from the Menninger Psychotherapy Research Project. Their study showed that introjective patients benefitted significantly from a psychoanalytic approach, through the development of more adaptive interpersonal capacities, whereas anaclitic patients tended to benefit more from supportive-expressive psychotherapy. In particular, anaclitic patients appeared to respond primarily to the supportive dimensions of the therapeutic process, whereas introjective patients responded more to the interpretative dimensions. Further, using data from the YaleRiggs study, Blatt and Ford (1994) showed that anaclitic and introjective patients appeared to change in dimensions most salient to their basic personality organization: Anaclitic patients changed primarily in the quality of their interpersonal relationships, whereas introjective patients showed primarily symptom reduction and changes in the efficiency of their cognitive functioning. For example, thought disorder in anaclitic patients was reduced primarily in forms that express boundary disturbances involving the merger or fusion of independent thoughts or concepts (i.e., contaminations and confabulations), whereas introjective patients showed reductions in thought-disordered responses that involve referential thinking (fabulized combinations) (Blatt et al., 2007).

This line of thinking is highly relevant to thinking about personality disorder. Individuals with dependent, histrionic or borderline personality disorder tend to show problems with interpersonal relationships at the expense of the development of feelings of 
autonomy and agency, whereas individuals with paranoid, schizoid, antisocial, narcissistic, or avoidant personality disorder tend to have more issues with self-definition at the expense of the development of the capacity for relatedness (Blatt, 2008). Blatt noted research indicating that borderline personality disorder (BPD) was the only personality disorder in which concerns about both relatedness and self-definition were elevated (Ouimette, Klein, Anderson, Riso, \& Lizardi, 1994). This is an intriguing early exploration of an idea that has been followed up more recently in an evaluation of a bi-factor model of personality disorder, in which a general factor and several specific factors of personality pathology accounted for the covariance among personality disorder criteria (Sharp et al., 2015). In the bi-factor model, all BPD criteria loaded only on to the general factor. Other personality disorders loaded either on to both the general factor and a specific factor, or largely only on to a specific factor. One implication of this finding is that BPD criteria may capture the core of personality pathology, or may be representative of all personality disorders. Yet, despite this common core of BPD, in terms of treatment approach, Blatt was one of the first to systematically document differences in changes in treatment between more anaclitic BPD patients—who are highly dependent and prone to feelings of abandonment - and those with more introjective features, often with comorbid obsessive-compulsive or paranoid features. Blatt's work with John Auerbach was truly pioneering in this regard (Blatt, 2008; Blatt \& Auerbach, 1988).

The idea of a general factor, or "p" factor, for psychopathology is a new and fastmoving area of research (Caspi et al., 2014; Lahey et al., 2012; Lahey et al., 2018; Olino et al., 2018; Patalay et al., 2015; Tackett et al., 2013). Blatt's dimensional approach to psychopathology, and his interest in the shared characteristics underpinning different diagnostic categories, were trailblazing ways of thinking that are now being taken up with increasing interest. But, crucially, Blatt never lost sight of the individual, clinical meaning of such thinking - showing how a focus on a general factor does not, and should not, be taken to 
suggest a general, one-size-fits-all model of treatment. In fact, he showed us how a dimensional approach should lead us in the opposite direction toward tailored thinking about the individual's treatment needs according to where they might be in the complex transaction between introjective and anaclitic processes, and how developmentally sensitive this everchanging transaction might be. He encapsulated this thus: "the need to consider the impact of the complex interactions among the characteristics of patients, therapists, and the treatment process on the therapeutic outcome, as well as the need to evaluate dimensions beyond symptom reduction" (Blatt, 2008, p. 241).

Blatt was also concerned with another issue associated with the question of Diagnostic and Statistical Manual (DSM) diagnostic categories - the problem of comorbidity (Luyten \& Blatt, 2007). Unease and dissatisfaction with the existing categorization of psychiatric disorder, as expressed in the DSM, is acknowledged throughout the field, and the arguments are well-rehearsed (Fonagy, Campbell, \& Bateman, 2016). In his dimensional model of developmental psychopathology, Blatt cut across diagnostic categories in a way that allowed for movement across and between diagnoses that is more congruent with the trajectories of mental health across the life course, particularly among individuals with more severe mental health difficulties. For example, there is high comorbidity between conduct disorder (externalizing) in adolescence and depression (internalizing) in later life. By conceptualizing depression as being either introjective or anaclitic in character, we can make sense of the apparent paradox: the continuity lies in the persistently introjective nature of the pathology rather than its externalizing/internalizing manifestation (Blatt, 2008). The polarity model of personality organization and psychopathology therefore creates a clinically useable framework that enables us to see what is shared by different forms of psychopathology and what might underpin comorbidity.

One of Blatt's further key contributions was the developmental nature of his model of 
personality development. Attachment theory played a crucial role in this regard, as testified by his collaboration with some of the major figures in this field (Beebe et al., 2007; Blatt \& Blass, 1990; Blatt \& Levy, 2003; Levy \& Blatt, 1999). Blatt, particularly in his work with Kenneth Levy, used the two-polarities model of interpersonal relatedness and self-definition to create links between early attachment style, the development of personality, and psychopathology. It was proposed (and later empirically confirmed) that an introjective developmental line was related to an avoidant attachment style, and an anaclitic line to preoccupied attachment (Blatt \& Homann, 1992; Blatt \& Marouidas, 1992; Levy \& Blatt, 1999; Levy, Blatt, \& Shaver, 1998). The focus on the interpersonal developmental line is characterized by exaggerated attempts to establish interpersonal relationships as noted in resistant-ambivalent attachment, with its fears of abandonment and compulsive care-seeking. On the other hand, avoidant attachment has been associated with a preoccupation with issues related to the introjective developmental line and with an introjective/self-critical type of depression, characterized by concerns about loss of self-esteem and feelings of worthlessness, blame, and guilt (Blatt \& Homann, 1992). This integration with attachment theory is rich in thinking about the development of personality organization, and simultaneously creates a framework for thinking about psychopathology.

The value of such a developmental approach goes without saying, given the exaggerated limitations of the DSM categorical system in the context of diagnosing disorder in childhood and adolescence (Lahey et al., 2008) and the vulnerability of these life stages to the emergence of disorder (Murphy \& Fonagy, 2013). Through his theory of dialectical transactions between relatedness and self-definition, Blatt generated a powerfully unifying and coherent conceptualization of the mind across the life course. By connecting attachment style thinking about how we understand psychopathology and personality styles that reflect our heuristic understanding of how we work as individuals, he arrived at a genuinely 
developmental, life-course approach to understanding the ever-changing complexity and sameness of an individual throughout life. In doing this, he was resolving questions that have hampered attempts to make sense of psychopathology in a way that chimes with subjective experience, clinical understanding, and empirical findings that have in different ways rendered conventional thinking about psychopathology incomplete.

Importantly, as noted, this approach also opened up new avenues for studying the psychological processes involved in therapeutic change. Blatt's work with David Zuroff and colleagues in the context of the National Institute of Mental Health Treatment of Depression Collaborative Research Program provided a major breakthrough in the field of psychotherapy research, as it found that the reactivation of the dialectic between autonomy and relatedness was a key therapeutic process (Blatt, Zuroff, Hawley, \& Auerbach, 2010; Shahar, Blatt, Zuroff, \& Pilkonis, 2003). These findings were later replicated by Vermote, Lowyck, and colleagues (Lowyck, Luyten, Vermote, Verhaest, \& Vansteelandt, 2017; Vermote et al., 2015) in relation to the treatment of patients with personality disorder. Collectively, these studies indicate how a more careful differentiation among patients presenting with apparently the same diagnosis could provide a more sophisticated insight into which treatment(s) could be most effective for which individual patients.

\section{Mentalizing, Epistemic Trust, and the Two-Polarities Model}

Thus far we have attempted to sketch something of the extent of Sidney Blatt's influence on the field in its widest sense. We will now attempt to convey how his work has shaped and informed, and is congruent with, our own thinking — particularly our own recent formulations on the role of attachment, mentalizing, and epistemic trust in a developmental approach to the emergence of psychopathology.

There are clear parallels between Blatt's thinking about attachment and the theory of 
mentalizing in the shared emphasis on trying to unpick the psychological processes at work behind the infant's translating of their attachment experiences to generate their own way of making sense of their mind in relation to the minds around them. The self-definition and relatedness dialectic clearly is in line with our proposition that mentalizing skills are acquired through the experience of being mentalized within the attachment relationship, and our emphasis on value to the child of having their mind simultaneously understood/empathized with, and recognized as separate and agentive (Fonagy, Gergely, Jurist, \& Target, 2002). Another related connection to Blatt's approach is the fact that a central part of mentalizing theory is the notion that balanced mentalizing requires the capacity to hold one's own mind in mind as well as other people's - in other words, having a healthy balance between interrelatedness and self-definition. Indeed, perhaps it is not a coincidence that the mentalizing model is also shaped by polarities, or dimensions. We have described the dimensions in mentalizing as (1) automatic versus controlled mentalizing, (2) mentalizing the self versus others, (3) internal versus external mentalizing, and (4) cognitive versus affective mentalizing (Fonagy \& Luyten, 2009). The premise of mentalizing therapeutic work is that effective treatment involves working to help the individual become "unstuck" from their position on any of these dimensions (Bateman \& Fonagy, 2016).

Another way in which our more recent thinking builds on Blatt's is in our attempt to suggest much wider implications for understanding psychopathology and personality development. The concept of epistemic trust has been at the heart of our most recent work, which has led to a shift toward thinking about psychopathology and resilience in a more systemic way (Fonagy, Luyten, Allison, \& Campbell, 2017a, 2017b). Recent elaborations of thinking about mentalizing have taken the argument one step further to point to another important function of attachment relationships. This is the development of epistemic trust, that is, trust in the authenticity and personal relevance of interpersonally transmitted 
knowledge. Epistemic trust enables social learning in an ever-changing social and cultural context and allows individuals to benefit from their social environment (Fonagy \& Allison, 2014; Fonagy, Luyten, \& Allison, 2015). The theory of natural pedagogy developed by Csibra and Gergely (2009) helps to clarify the key issues here. Human beings are faced with a major learnability problem: they are born into a world that is populated with objects, attributes, and customs whose function or use is epistemically opaque (i.e., not obvious from their appearance). They have thus evolved to both teach and learn new and relevant cultural information rapidly. Human communication is specifically adapted to allow the transmission of epistemically opaque information, and the communication of such knowledge is enabled by an epistemically trusting relationship. Epistemic trust allows the recipient of the information being conveyed to relax their natural, epistemic vigilance - a vigilance that is self-protective and naturally occurring because, after all, it is not in one's interest to believe everything indiscriminately. The relaxation of epistemic vigilance allows individuals to accept that what they are being told matters to them.

This has led to a modulation of how the significance of attachment is understood, according to which attachment is considered as a highly important mode of transmitting social learning in infancy. Although attachment is a universal human impulse, it is but one element of developmental social learning and, indeed, different social environments are likely to trigger different attachment styles as being more adaptive (Fonagy et al., 2017a, 2017b). In terms of psychopathology, we suggest that the most significant implication of the developmental triad of attachment, mentalizing, and epistemic trust lies in the consequences of a breakdown in epistemic trust. We suggest that many—if not all—types of psychopathology might be characterized by temporary or permanent disruption of epistemic trust and the social learning process it enables. This social learning/epistemic trust perspective on psychopathology allows us to accommodate a wider social context — and 
differing cultural norms - than have normally been accommodated by either attachment theory or psychoanalysis. By appreciating the role of the social environment, we can come to a broader explanatory view of different cultures and behaviors that is in keeping with evolutionary thinking. The human brain is adapted to be highly variable, complex, and socially contingent. The theory of epistemic trust and social learning from the immediate family and culture can help us account for the relationship between individual behaviors and the broader cultural and socioemotional context in which an individual has been raised, and the inherent adaptive nature of these behaviors, despite their sometimes maladaptive consequences. Lower levels of mentalizing, greater aggressiveness, and higher sensitivity to perceived threats, for instance, should be seen from this perspective as adaptive responses to certain cultural environments (e.g., hypersensitivity to issues of shame and honor; lack of faith in the support of external authorities and institutions) in which families are psychologically enculturating their children, instead of reflecting a "deficit" or "vulnerability."

To relate this to Blatt's (2008) thinking, certain environments, both emotional and cultural, will stimulate a more introjective form of thinking —one in which self-definition is a prime concern. This can conflate dangerously with a general tendency for stereotypically male thinking to be located on the introjective end of the spectrum, and for adolescent males to enact this thinking in externalizing ways (Fonagy \& Luyten, 2018). There is also a parallel between the concept of the alien self (Fonagy \& Luyten, 2009) and Blatt's description of a strongly introjective form of thinking. They both make sense of the heightened and extreme anxiety — and hostility — that can arise from the threat of reprisal or attack on the self. Similarly, anaclitic thinking has a role to play here. For some individuals, submissive and seemingly self-defeating behavior may be the only way to survive in a family and/or broader sociocultural context that prioritizes the importance of the group and/or certain group 
members over the importance of the individuals. Similarly, a tendency to sexualization of relationships or extreme promiscuity may reflect an adaptation strategy when faced with harsh conditions marked by a lack of love, warmth, and validation.

Adolescence is a period of considerable challenges in terms of balancing the twin demands of relatedness and agency/autonomy (Luyten \& Fonagy, 2018). We have suggested that challenges related to balancing these two imperatives constitute two major pathways to child and adolescent depression in particular, and psychopathology more generally (Luyten \& Fonagy, 2018), demonstrating the continuing influence of Blatt's ideas on our own thinking.

According to our thinking, an unbalanced relationship between introjective and anaclitic forms of thinking results in the enduring patterns of dysfunction associated with personality disorder because they create a lack of resilience. They preclude access to the broaden-and-build strategies that protect more resilient individuals from the effects of interpersonal stress: more resilient individuals have access to the dual and mutually strengthening strategies of being able to (a) recruit the support of others and (b) retain a sufficient hold over their own sense of self without being overwhelmed by either the alien self or a sense of the complete fragmentation of the self.

This idea of resilience being driven by the capacity to benefit from the social environment, which is enabled by epistemic trust, is also in keeping with Blatt's work on rethinking how we conceptualize psychopathology. As well as proposing that epistemic trust is at the heart of therapeutic change, we are, even more broadly and integratively, proposing that it may be associated with a common factor across different forms of psychopathology. An individual with a high $\mathrm{p}$ factor score - that is, one with an increased risk of psychopathology — is one who, because of developmental adversity (whether biological or social), is in a state of epistemic hypervigilance and epistemic mistrust. If this conceptualization is true, it may have major consequences for psychosocial interventions. It 
would mean, for instance, that people with relatively low p factor scores might be most responsive to psychosocial interventions. A depressed patient with a low $\mathrm{p}$ factor score may recover with the help of brief cognitive-behavioral therapy or psychodynamic therapy, perhaps even when delivered via an internet-based platform. These patients may be relatively "easy to reach" in terms of treatment because they are open to social learning, and thus more open to any form of therapeutic intervention. We suggest that the normal developmental outcome of having experienced reasonably consistent marked mirroring is that it generates a sense of agency and supports the emergence of balanced mentalizing and, subsequently, salutogenesis (Fonagy et al., 2017a, 2017b). In contrast, a depressed patient with a high $\mathrm{p}$ factor score who is suffering from high levels of comorbidity, longer-term difficulties, and greater impairment is likely to show intense treatment resistance because of their high levels of epistemic mistrust or even outright epistemic freezing. We consider it likely that such patients will require longer-term therapy to first stimulate epistemic trust and openness, consistent with Blatt's assumption that the hallmark of psychopathology is rigidity, that is, the individual's reliance on the same models of relating to the self and others in an environment that is constantly changing. Like Blatt, we consider these rigid templates for relating to the self and others as attempts to adapt to biological and environmental factors and challenges, rather than vulnerability factors in the traditional meaning of the word. Hence, they present understandable attempts at adaptation, however maladaptive their outcomes may be. Further, we consider an intersubjective process where these rigid patterns are examined in the context of a relationship with an empathic and understanding person to hold the key to therapeutic change. Hence, much like Blatt (Blatt \& Behrends, 1987), we see a clear parallel between normal development and the therapeutic process. It is in the back-and-forth of experiences of mutuality and separation in the therapeutic relationship, of understanding and misunderstanding, that the patient increasingly feels understood by another mind - that is, the 
CONTRIBUTIONS OF SIDNEY J. BLATT

patient increasingly feels recognized as an agent, which restores their capacity for mentalizing and epistemic trust, opening them up to the process of salutogenesis. The selfcritical patient increasingly feels respect and valued, counteracting their often deeply rooted conviction of being worthless, and they are then enabled to see and feel that relationships do matter and that others can be trusted and are not necessarily critical and deprecating. The dependent individual acquires a sense of self-worth and autonomy via the very same process, and, through repeated experiences of understanding and misunderstanding, increasingly realizes that others — beginning with the therapist — may genuinely care, and will not abandon and reject them. Thus, in any successful treatment, there is a reactivation of the synergistic, dialectic interaction between autonomy and relatedness, much as in normal development. We would add that this dialectic interaction and its reactivation are facilitated enormously by the capacity for mentalizing and epistemic trust.

\section{Conclusions}

Sidney J. Blatt was one of the giants of psychoanalytic developmental psychopathology. He was able to integrate knowledge and findings from fields as diverse as personality theory, psychopathology, developmental psychology, psychotherapy research, and neuroscience. His major theoretical, empirical, and clinical contributions to psychoanalysis, psychology, and psychiatry testify not only to his capacity for autonomy and agency, but also to his almost unique capacity for collaboration. As in his work, autonomy and relatedness were the central dimensions in his life. The long list of his collaborators and co-authors stands as a unique testimony to his capacity to form lifelong collaborations and friendships.

With regard to our own thinking, Blatt's work has played a decisive role in our realization that the origins of human subjectivity are to be found in the dialectic interaction 
CONTRIBUTIONS OF SIDNEY J. BLATT

between experiences of relatedness and autonomy. Or, as he so fondly used to say, in experiences of mutuality and separation. Blatt's views have not only shaped our scientific thinking in ways that until recently we had only begun to fully realize; they have also made our lives and relationships much richer. For this we can only be grateful, and we look forward to further exploring this dialectic, and its role in normal and disrupted development, in the years to come.

\section{References}

Auerbach, J. S. (2016). Sidney Blatt's contributions to personality assessment. Journal of Personality Assessment, 98, 1-4. doi: 10.1080/00223891.2015.1107728

Bateman, A., \& Fonagy, P. (2016). Mentalization-based treatment for personality disorders: A practical guide. Oxford, UK: Oxford University Press.

Beebe, B., Jaffe, J., Buck, K., Chen, H., Cohen, P., Blatt, S., . . Andrews, H. (2007). Sixweek postpartum maternal self-criticism and dependency and 4-month mother-infant self- and interactive contingencies. Developmental Psychology, 43, 1360-1376. doi: $10.1037 / 0012-1649.43 .6 .1360$

Blatt, S., \& Ford, T. Q. (1994). Therapeutic change: An object relations approach. New York, NY: Plenum Press.

Blatt, S. J. (1992). The differential affect of psychotherapy and psychoanalysis with anaclitic and introjective patients: The Menninger Psychotherapy Research Project revisited. Journal of the American Psychoanalytic Association, 40, 691-724.

Blatt, S. J. (2004). Experiences of depression: Theoretical, clinical and research perspectives. Washington, DC: American Psychological Association.

Blatt, S. J. (2008). Polarities of experience: Relatedness and self definition in personality development, psychopathology, and the therapeutic process. Washington, DC: 
CONTRIBUTIONS OF SIDNEY J. BLATT

American Psychological Association.

Blatt, S. J., \& Auerbach, J. S. (1988). Differential cognitive disturbances in three types of borderline patients. Journal of Personality Disorders, 2, 198-211. doi:

10.1521/pedi.1988.2.3.198

Blatt, S. J., \& Behrends, R. S. (1987). Internalization, separation-individuation, and the nature of therapeutic action. International Journal of Psychoanalysis, 68, 279-297.

Blatt, S. J., Besser, A., \& Ford, R. Q. (2007). Two primary configurations of psychopathology and change in thought disorder in long-term intensive inpatient treatment of seriously disturbed young adults. American Journal of Psychiatry, 164, $1561-1567$.

Blatt, S. J., \& Blass, R. (1996). Relatedness and self definition: A dialectic model of personality development. In G. G. Noam \& K. W. Fischer (Eds.), Development and vulnerabilities in close relationships (pp. 309-338). New York, NY: Lawrence Erlbaum Associates.

Blatt, S. J., \& Blass, R. B. (1990). Attachment and separateness: A dialectical model of the products and processes of development throughout the life cycle. Psychoanalytic Study of the Child, 45, 107-127.

Blatt, S. J., \& Homann, E. (1992). Parent-child interaction in the etiology of depression. Clinical Psychology Review, 12, 47-91.

Blatt, S. J., \& Levy, K. N. (2003). Attachment theory, psychoanalysis, personality development, and psychopathology. Psychoanalytic Inquiry, 23, 102-150. doi: $10.1080 / 07351692309349028$

Blatt, S. J., \& Luyten, P. (2009). A structural-developmental psychodynamic approach to psychopathology: Two polarities of experience across the life span. Development and Psychopathology, 21, 793-814. doi: 10.1017/S0954579409000431 
Blatt, S. J., \& Marouidas, C. (1992). Convergances among psychoanalytic and cognitivebehavioral theories of depression. Psychoanalytic Psychology, 9, 157-190.

Blatt, S. J., \& Shahar, G. (2004). Psychoanalysis — with whom, for what, and how? Comparisons with psychotherapy. Journal of the American Psychoanalytic Association, 52, 393-447. doi: 10.1177/00030651040520020401

Blatt, S. J., Zuroff, D. C., Hawley, L. L., \& Auerbach, J. S. (2010). Predictors of sustained therapeutic change. Psychotherapy Research, 20, 37-54. doi:

$10.1080 / 10503300903121080$

Caspi, A., Houts, R. M., Belsky, D. W., Goldman-Mellor, S. J., Harrington, H., Israel, S., . . . Moffitt, T. E. (2014). The p factor: One general psychopathology factor in the structure of psychiatric disorders? Clinical Psychological Science, 2, 119-137. doi: $10.1177 / 2167702613497473$

Csibra, G., \& Gergely, G. (2009). Natural pedagogy. Trends in Cognitive Sciences, 13, 148153. doi: 10.1016/j.tics.2009.01.005

Fertuck, E. A., Bucci, W., Blatt, S. J., \& Ford, R. Q. (2004). Verbal representation and therapeutic change in anaclitic and introjective patients. Psychotherapy: Theory, Research, Practice, Training, 41, 13-25. doi: 10.1037/0033-3204.41.1.13

Fonagy, P., \& Allison, E. (2014). The role of mentalizing and epistemic trust in the therapeutic relationship. Psychotherapy, 51, 372-380. doi: 10.1037/a0036505

Fonagy, P., Campbell, C., \& Bateman, A. W. (2016). Update on diagnostic issues for borderline personality disorder. Psychiatric Times. Retrieved from http://www.psychiatrictimes.com/cme/update-diagnostic-issues-borderlinepersonality-disorder

Fonagy, P., Gergely, G., Jurist, E., \& Target, M. (2002). Affect regulation, mentalization, and the development of the self. New York, NY: Other Press. 
CONTRIBUTIONS OF SIDNEY J. BLATT

Fonagy, P., \& Luyten, P. (2009). A developmental, mentalization-based approach to the understanding and treatment of borderline personality disorder. Development and Psychopathology, 21, 1355-1381. doi: 10.1017/S0954579409990198

Fonagy, P., \& Luyten, P. (2018). Conduct problems in youth and the RDoC approach: A developmental, evolutionary-based view. Clinical Psychology Review, 64, 57-76. doi: 10.1016/j.cpr.2017.08.010

Fonagy, P., Luyten, P., \& Allison, E. (2015). Epistemic petrification and the restoration of epistemic trust: A new conceptualization of borderline personality disorder and its psychosocial treatment. Journal of Personality Disorders, 29, 575-609. doi: 10.1521/pedi.2015.29.5.575

Fonagy, P., Luyten, P., Allison, E., \& Campbell, C. (2017a). What we have changed our minds about: Part 1. Borderline personality disorder as a limitation of resilience. Borderline Personality Disorder and Emotion Dysregulation, 4, 11. doi: $10.1186 / \mathrm{s} 40479-017-0061-9$

Fonagy, P., Luyten, P., Allison, E., \& Campbell, C. (2017b). What we have changed our minds about: Part 2. Borderline personality disorder, epistemic trust and the developmental significance of social communication. Borderline Personality Disorder and Emotion Dysregulation, 4, 9. doi: 10.1186/s40479-017-0062-8

Ghaemi, S. N. (2018). After the failure of DSM: Clinical research on psychiatric diagnosis. World Psychiatry, 17, 301-302. doi: 10.1002/wps.20563

Kapur, S., Phillips, A. G., \& Insel, T. R. (2012). Why has it taken so long for biological psychiatry to develop clinical tests and what to do about it? Molecular Psychiatry, 17, 1174-1179. doi: 10.1038/mp.2012.105

Lahey, B. B., Applegate, B., Hakes, J. K., Zald, D. H., Hariri, A. R., \& Rathouz, P. J. (2012). Is there a general factor of prevalent psychopathology during adulthood? Journal of 
Abnormal Psychology, 121, 971-977. doi: 10.1037/a0028355

Lahey, B. B., Rathouz, P. J., Van Hulle, C., Urbano, R. C., Krueger, R. F., Applegate, B., . . . Waldman, I. D. (2008). Testing structural models of DSM-IV symptoms of common forms of child and adolescent psychopathology. Journal of Abnormal Child Psychology, 36, 187-206. doi: 10.1007/s10802-007-9169-5

Lahey, B. B., Zald, D. H., Perkins, S. F., Villalta-Gil, V., Werts, K. B., Van Hulle, C. A., . . . Waldman, I. D. (2018). Measuring the hierarchical general factor model of psychopathology in young adults. International Journal of Methods in Psychiatric Research, 27 doi: 10.1002/mpr.1593

Levy, K. N., \& Blatt, S. J. (1999). Attachment theory and psychoanalysis: Further differentiation within insecure attachment patterns. Psychoanalytic Inquiry, 19, 541575.

Levy, K. N., Blatt, S. J., \& Shaver, P. R. (1998). Attachment styles and parental representations. Journal of Personality and Social Psychology, 74, 407-419.

Lowyck, B., Luyten, P., Vermote, R., Verhaest, Y., \& Vansteelandt, K. (2017). Self-critical perfectionism, dependency, and symptomatic distress in patients with personality disorder during hospitalization-based psychodynamic treatment: A parallel process growth modeling approach. Personality Disroders: Theory, Research, and Treatment, 8, 268-274. doi: 10.1037/per0000189

Luyten, P. (2015). Sidney J. Blatt (1928-2014). American Psychologist, 70, 476-476. doi: $10.1037 / \mathrm{a} 0039243$

Luyten, P., \& Blatt, S. J. (2007). Looking back towards the future: is it time to change the DSM approach to psychiatric disorders? The case of depression. Psychiatry (Edgmont), 70, 85-99. doi: 10.1521/psyc.2007.70.2.85

Luyten, P., \& Blatt, S. J. (2013). Interpersonal relatedness and self-definition in normal and 
disrupted personality development: Retrospect and prospect. American Psychologist, 68, 172-183. doi: 10.1037/a0032243

Luyten, P., \& Fonagy, P. (2018). The stress-reward-mentalizing model of depression: An integrative developmental cascade approach to child and adolescent depressive disorder based on the Research Domain Criteria (RDoC) approach. Clinical Psychology Review, 64, 87-98. doi: 10.1016/j.cpr.2017.09.008

Murphy, M., \& Fonagy, P. (2013). Mental health problems in children and young people. In Our children deserve better: Prevention pays. Annual report of the Chief Medical Officer 2012 (pp. 176-188). London, UK: Department of Health.

Oasi, O., \& Auerbach, J. (2017). Introduction to the issue in honor of Sidney Blatt. Research in Psychotherapy: Psychopathology, Process and Outcome, 20, 1-2. doi: 10.4081/ripppo.2017.268

Olino, T. M., Bufferd, S. J., Dougherty, L. R., Dyson, M. W., Carlson, G. A., \& Klein, D. N. (2018). The development of latent dimensions of psychopathology across early childhood: Stability of dimensions and moderators of change. Journal of Abnormal Child Psychology, 46, 1373-1383. doi: 10.1007/s10802-018-0398-6

Ouimette, P. C., Klein, D. N., Anderson, R., Riso, L. P., \& Lizardi, H. (1994). Relationship of sociotropy/autonomy and dependency/self-criticism to DSM-III-R personality disorders. Journal of Abnormal Psychology, 103, 743-749. doi: 10.1037/0021843X.103.4.743

Patalay, P., Fonagy, P., Deighton, J., Belsky, J., Vostanis, P., \& Wolpert, M. (2015). A general psychopathology factor in early adolescence. British Journal of Psychiatry, 207, 15-22. doi: 10.1192/bjp.bp.114.149591

Rutter, M. (2013). Developmental psychopathology: A paradigm shift or just a relabeling? Development and Psychopathology, 25, 1201-1213. doi: 


\section{$10.1017 / \mathrm{S} 0954579413000564$}

Shahar, G., Blatt, S. J., Zuroff, D. C., \& Pilkonis, P. A. (2003). Role of perfectionism and personality disorder features in response to brief treatment for depression. Journal of Consulting and Clinical Psychology, 71, 629-633.

Shahar, G., \& Mayes, L. C. (2017). Sidney Blatt's psychoanalytic legacy: An introduction. Journal of the American Psychoanalytic Association, 65, 453-456. doi: $10.1177 / 0003065117709003$

Sharp, C., Wright, A. G., Fowler, J. C., Frueh, B. C., Allen, J. G., Oldham, J., \& Clark, L. A. (2015). The structure of personality pathology: Both general ('g') and specific ('s') factors? Journal of Abnormal Psychology, 124, 387-398. doi: 10.1037/abn0000033

Tackett, J. L., Lahey, B. B., van Hulle, C., Waldman, I., Krueger, R. F., \& Rathouz, P. J. (2013). Common genetic influences on negative emotionality and a general psychopathology factor in childhood and adolescence. Journal of Abnormal Psychology, 122, 1142-1153. doi: 10.1037/a0034151

Uher, R., \& Rutter, M. (2012). Basing psychiatric classification on scientific foundation: Problems and prospects. International Review of Psychiatry, 24, 591-605. doi: $10.3109 / 09540261.2012 .721346$

Vermote, R., Luyten, P., Verhaest, Y., Vandeneede, B., Vertommen, H., \& Lowyck, B. (2015). A psychoanalytically informed hospitalization-based treatment of personality disorders. International Journal of Psychoanalysis, 96, 817-843. doi: 10.1111/17458315.12394

Zachar, P., \& Kendler, K. S. (2017). The philosophy of nosology. Annual Review of Clinical Psychology, 13, 49-71. doi: 10.1146/annurev-clinpsy-032816-045020 